\title{
Microstructures and mechanical properties of commercial titanium foils processed via the melt overflow process
}

\author{
M.L. Weaver ${ }^{1, a, *}$, H. Garmestani ${ }^{b}$ \\ ${ }^{a}$ Department of Metallurgical and Materials Engineering, University of Alabama, Tuscaloosa, AL 35487-0202, USA \\ ${ }^{\mathrm{b}}$ Department of Mechanical Engineering, FAMU-FSU College of Engineering, 2525 Pottsdamer St., Tallahassee, FL 32310-2175, USA
}

Received 11 July 1997; received in revised form 1 October 1997

\begin{abstract}
Microstructures, crystallographic textures, and mechanical properties have been investigated in commercial titanium alloy strips and foils processed via the melt overflow rapid solidification technology (MORST) technique. The direct cast (DC) foils were fully dense and exhibited equiaxed transformed grain structures and weak $\{11 \overline{2} 0\} / /$ normal direction solidification textures. After cold rolling, split $\{0002\}$ textures were observed in both DC and ingot metallurgy (IM) processed foils with the basal poles concentrated approximately $30^{\circ}$ from the normal direction towards the transverse direction. Crystallite orientation distribution

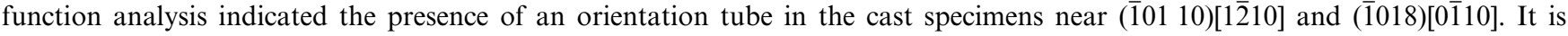
suggested that these textures are a result of the lattice rotations and nonuniform cooling that occur during the casting process. After rolling and annealing, main texture orientations were observed. The mechanical properties of the DC foils were comparable to IM foils. The results suggest that high quality titanium foils can be processed via MORST without the need for costly and wasteful hot rolling and annealing steps resulting in reduced processing costs. (C) 1998 Elsevier Science S.A. All rights reserved.
\end{abstract}

Keywords: Crystallographic; Alloy; Titanium; Direct cast; Annealing

\section{Introduction}

The processing of titanium foils by commercial ingot metallurgy (IM) techniques involves casting ingots, hot forging into billets, followed by several hot rolling, heat treatment, and surface grinding sequences to produce plate or sheet that is suitable for cold rolling to foil gauge. Using these techniques, processing losses exceeding $50 \%$ are not uncommon making commercial production of titanium foils very expensive. Recently, Gaspar et al. [1-4] have reported success in direct casting strips of commercial titanium alloys and titanium-based ordered intermetallic compounds using a single-chill-roll casting technique called melt overflow rapid solidification technology (MORST). Using this technique, near-net-shape foils have been continuously cast into $\sim 0.5 \mathrm{~mm}$ thick $\times 100 \mathrm{~mm}$ wide $\times 3000 \mathrm{~mm}$

* Corresponding author. Tel.: + 1205 3487073; fax: + 1205 3482164; e-mail: mweaver@coe.eng.ua.edu

${ }^{1}$ Formerly Research Associate at the Center for Nonlinear and Nonequilibrium AeroScience, Florida A\&M University, 1800 E. Paul Dirac Road, Tallahassee, FL 32306-4005. long strips which were successfully ground, cold rolled, or hot pack rolled to foil gauge ( $\leq 100 \mu \mathrm{m}$ thickness). In comparison to IM processing techniques, the potential advantages of foil production from direct cast (DC) strips are improved purity, increased chemical homogeneity, and a reduction in processing losses resulting in lower processing costs. While the microstructures, mechanical properties, and textures of IM titanium alloys have been extensively characterized, they have not yet been addressed for DC titanium. In this paper, the microstructures, mechanical properties, and crystallographic textures developed in DC strips and in cold rolled foils produced from DC precursors are compared with those of IM titanium foils.

\section{Experimental procedure}

Titanium strips were cast in the plasma melt overflow furnace at Ribbon Technology, Columbus, $\mathrm{OH}$. The plasma melt overflow furnace combines plasma arc melting in a cold copper hearth with MORST by 
Table 1

Chemical compositions of titanium strips/foils investigated

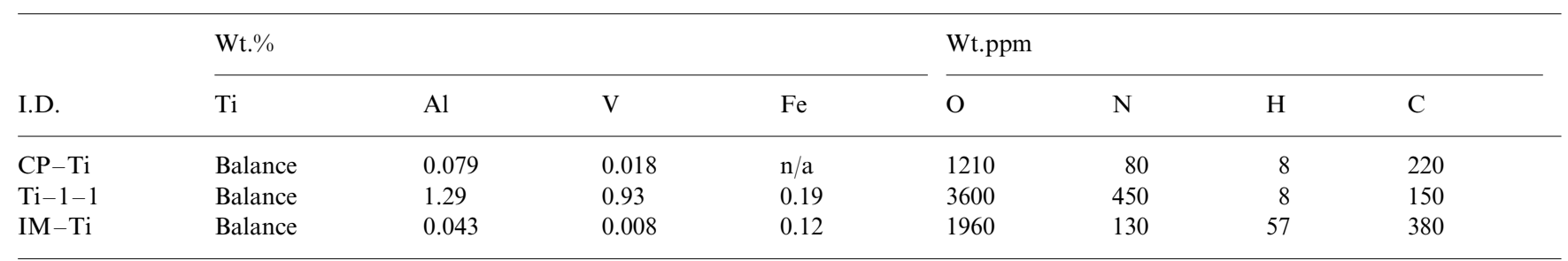

rotating the cold copper hearth about the same axis of rotation as the chill roll to overflow liquid onto the circumference of the chill roll [1-4]. The chemical compositions of the DC titanium strip/foil and of a commercial IM foil supplied for comparison purposes are given in Table 1. The DC material was prepared from commercial purity (CP) titanium [2]. However, during processing, the $\mathrm{CP}$ feed material for one of the DC strips was accidentally mixed with $\approx 20 \% \mathrm{Ti}-6 \mathrm{Al}-$ $4 \mathrm{~V}$ scrap resulting in an alloy of approximate composition $\mathrm{Ti}-1.29 \mathrm{Al}-0.93 \mathrm{~V}(\mathrm{Ti}-1-1)$. This addition was not discovered until the alloy strip had been cast, cold rolled and annealed $(\mathrm{CR}+\mathrm{A})$.

The foils used in this study were prepared using a two step rolling process where the cast strip was initially cold rolled to a $40-50 \%$ reduction in thickness. The rolled strip was then vacuum annealed at $700^{\circ} \mathrm{C}$ for $2 \mathrm{~h}$. The resulting 'thick foil' was then cold rolled to an $80 \%$ reduction in thickness corresponding to a foil thickness of $0.05 \mathrm{~mm}$ ('thin foil') followed by vacuum annealing at $700^{\circ} \mathrm{C}$ for $2 \mathrm{~h}$. All specimens were cold rolled parallel to the casting direction. An IM-Ti foil of thickness $0.07 \mathrm{~mm}$ was obtained for comparison purposes.

For texture analysis, portions of each alloy sheet were cut into small pieces, mechanically polished, and etched with Kroll's reagent to remove any residual deformation layers. Texture variations were measured through the thickness of each sheet using the X-ray diffraction technique on a Philips X'Pert PW3040 MRD X-ray diffractometer operating at $40 \mathrm{kV}$ and 45 $\mathrm{mA}$. The following incomplete pole figures were measured using $\mathrm{Ni}$ filtered $\mathrm{CuK} \alpha$ radiation to determine textures in the $\alpha$ phase: $\{0002\},\{10 \overline{1} 0\},\{10 \overline{1} 1\},\{11 \overline{2} 0\}$, $\{10 \overline{1} 2\}$, and $\{11 \overline{2} 2\}$. From this data, crystallite orientation distribution functions (CODs) were calculated using the popLA software package [5] from which the experimental pole figures were re-constructed. In the case of hexagonal metals, most of the important orientations which appear in the discussions of the rolling texture are located on the $\phi=0$ and $30^{\circ}$ sections of the CODs. Thus, the calculated results were expressed in terms of these sections.

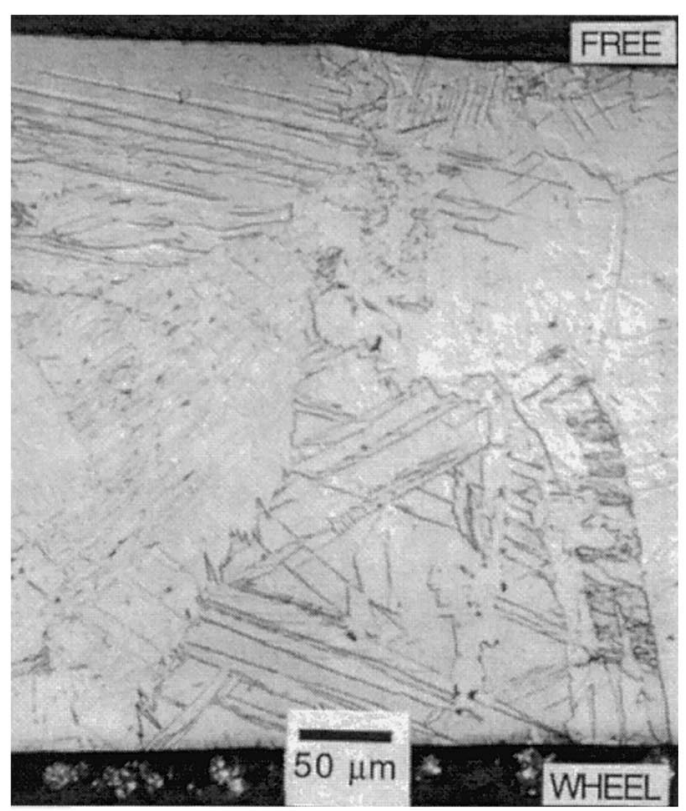

(a)



(b)

Fig. 1. Light optical micrographs of the microstructures observed in as-cast titanium sheets. (a) $\mathrm{CP}-\mathrm{Ti}$ and (b) $\mathrm{Ti}-1-1$. 


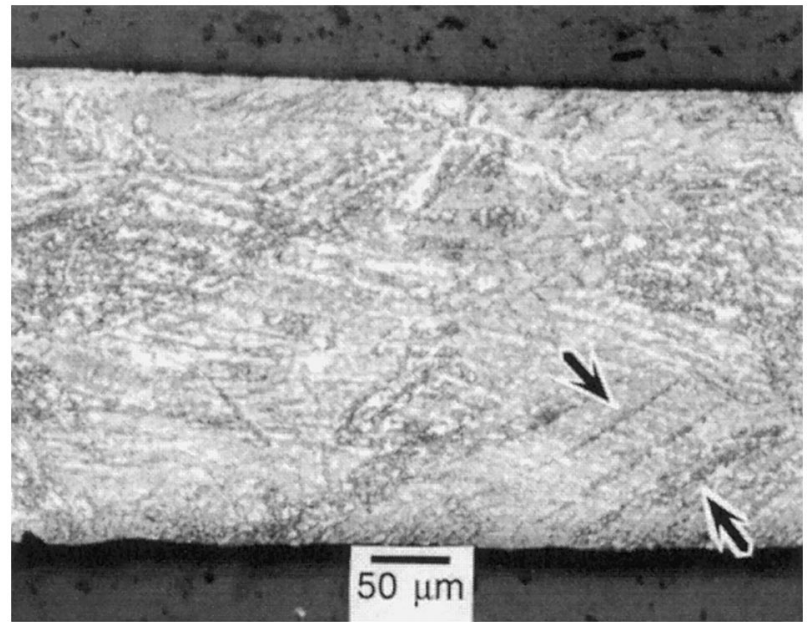

Fig. 2. Light optical micrograph of the microstructure observed in $\mathrm{CP}-\mathrm{Ti}$ after $40 \%$ cold deformation.

Dog-bone shaped tensile specimens $45 \mathrm{~mm}$ long with gage dimensions of $11.4 \mathrm{~mm} \mathrm{~L} \times 6.4 \mathrm{~mm} \mathrm{~W}$ were machined from the cold rolled foils. Multiple specimens were machined parallel to and perpendicular to the rolling direction. Tensile tests were performed at room temperature on a computer interactive ATS Model 1630 universal testing machine operated at constant crosshead velocities corresponding to initial strain rates of $1 \times 10^{-4}$ and $7 \times 10^{-3} \mathrm{~s}^{-1}$.

\section{Results}

\subsection{Microstructure and rolling behavior}

Typical optical microstructures for the DC strips are shown in Fig. 1. Large columnar grains originating from the wheel surface were observed with grain diameters ranging from 35 to $200 \mu \mathrm{m}$. In many sections of the strips, the columnar structures broke down and became more equiaxed as the free surface was approached. During solid-state cooling, the grains transformed martensitically to a mixture of acicular and serrated $\alpha$ phases as determined via optical microscopy and XRD. In general, the strips were fully dense and contained no visible casting porosity or cracks. In all cases, the free surfaces of each strip were rougher in appearance than the wheel surfaces.

Cold rolling was accomplished at room temperature without any noticeable cracking or splitting. Cold rolling to a $40 \%$ reduction in thickness resulted in breakup of the primary alpha and beta grains and in their elongation parallel to the rolling direction (Fig. 2). In addition, all surface roughness was removed and diffuse shear bands, with an angle of $\approx 30^{\circ}$ to the rolling direction, were observed (indicated by the ar- rows in Fig. 2). After cold rolling and subsequent annealing, microstructures consisting of fine equiaxed $\alpha$ grains were observed in all of the foils with nominal grain diameters approaching $18 \mu \mathrm{m}$ (Fig. 3).

\subsection{Texture}

Pole figures observed in the direct cast $\mathrm{CP}-\mathrm{Ti}$ and Ti-1-1 specimens are illustrated in Fig. 4. In both
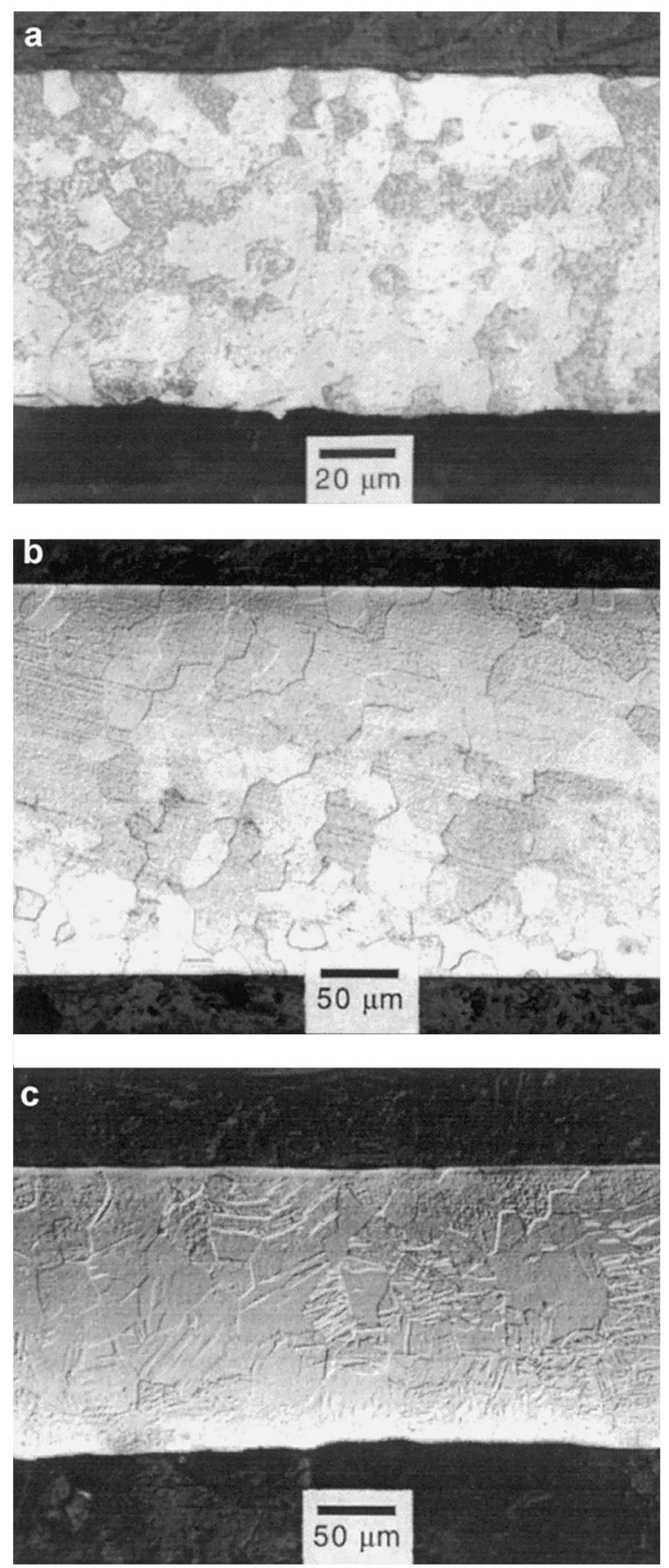

Fig. 3. Light optical micrographs of the microstructures observed in cold rolled titanium foils. (a) IM CP-Ti, (b) $\mathrm{CP}-\mathrm{Ti}$, and (c) $\mathrm{Ti}-1-1$. 


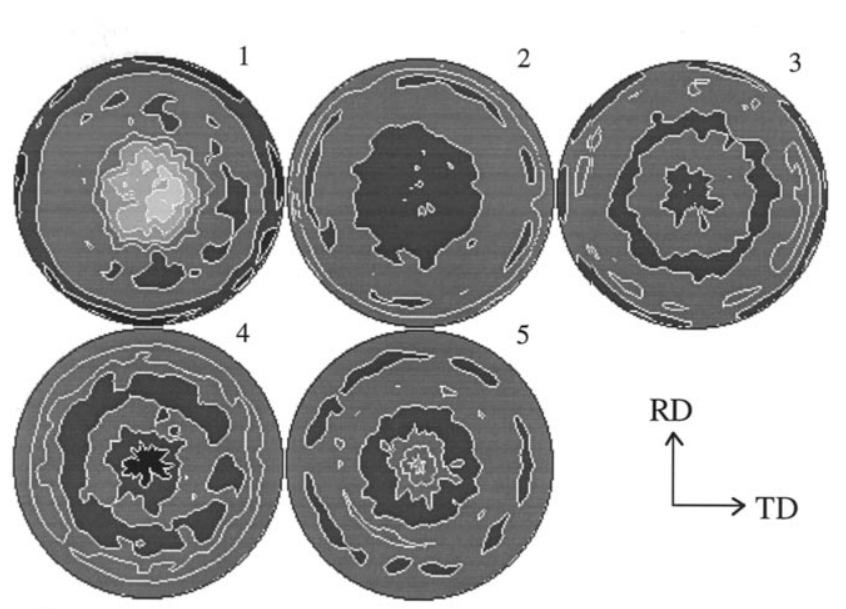

strength $=1.14$ $\max .=1.88$

(a)
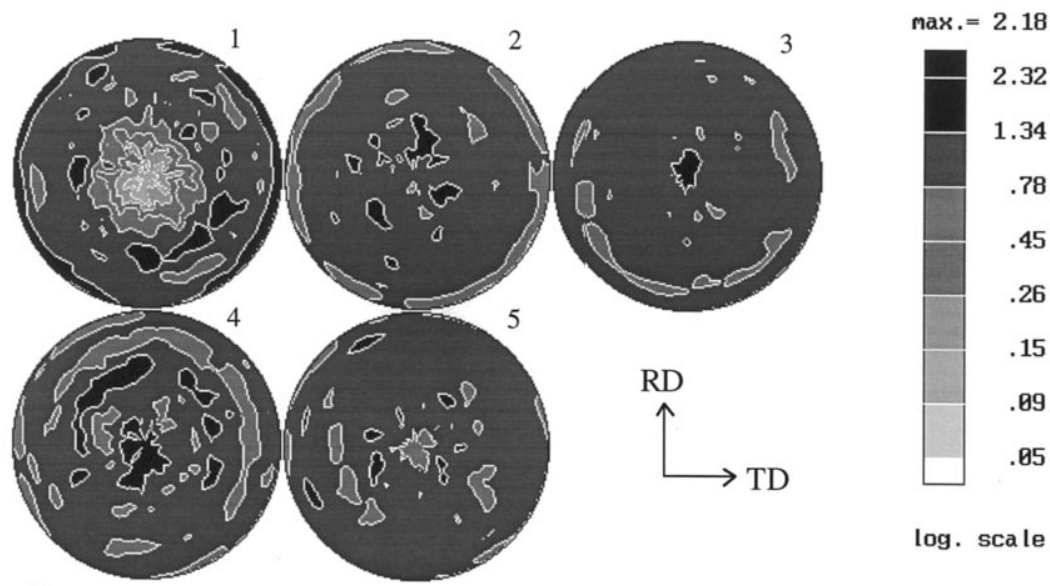

log. scale

(b)

Fig. 4. Indirect pole figures for DC titanium sheets. (a) $\mathrm{CP}-\mathrm{Ti}$ and (b) $\mathrm{Ti}-1-1$ (TD is horizontal). $1=\{0002\}, 2=\{10 \overline{1} 0\}, 3=\{10 \overline{1} 1\}, 4=\{10 \overline{2} 0\}$, and $5=\{11 \overline{2} 0\}$.

cases, very weak $(\sim 2 \times$ random $)$ fiber components were observed with the major poles oriented parallel to the sheet normal in the [11 20$]$ direction indicating some degree of directional solidification. Some components nearly parallel to the casting and transverse directions were also observed in the $\{0002\}$ pole figure. Textures
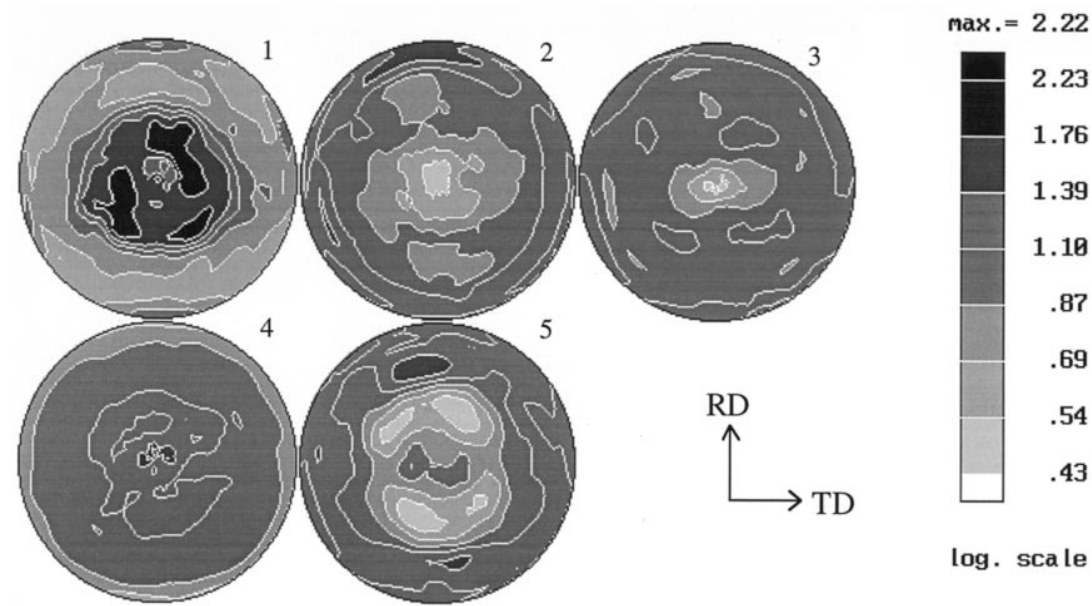

log. scale

Fig. 5. Indirect pole figures for $\mathrm{CP}-\mathrm{Ti}$ sheets cold rolled $40 \%$ at room temperature. $1=\{0002\}, 2=\{10 \overline{1} 0\}, 3=\{10 \overline{1} 1\}, 4=\{10 \overline{1} 2\}$, and $5=\{11 \overline{2} 0\}$. 


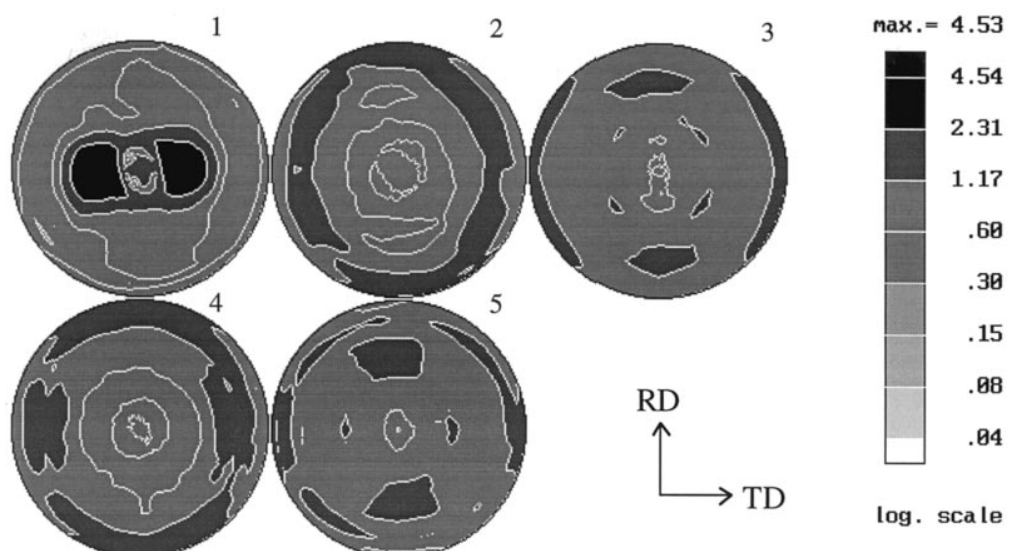

(a)
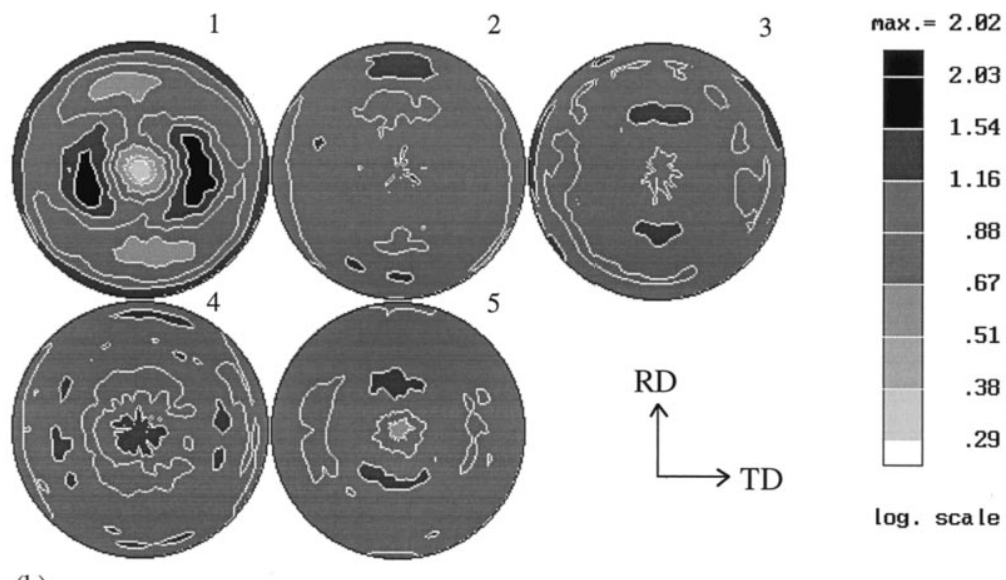

(b)
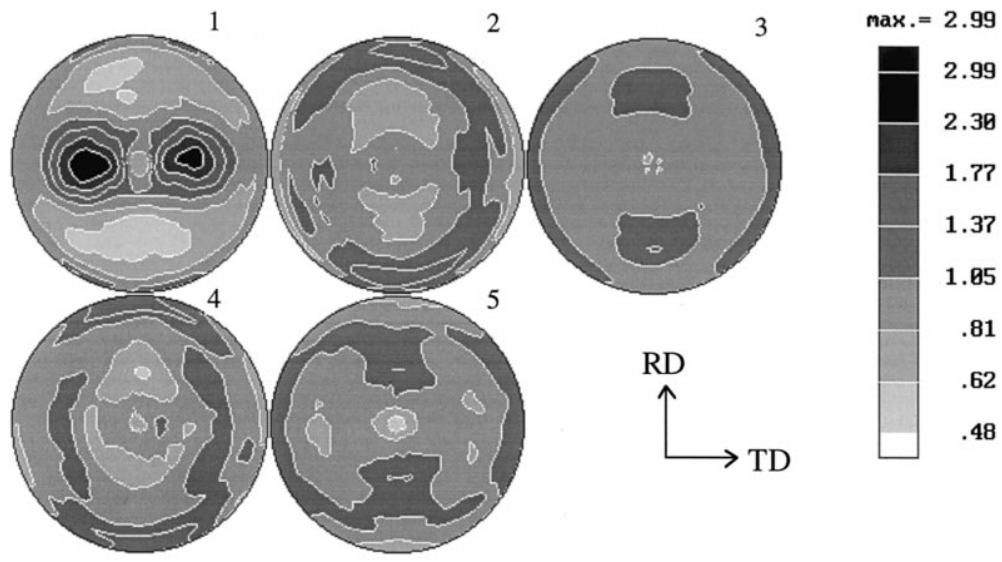

(c)

Fig. 6. Indirect pole figures for titanium foils annealed at $700^{\circ} \mathrm{C}$ for $2 \mathrm{~h} .1=\{0002\}, 2=\{10 \overline{1} 0\}, 3=\{10 \overline{1} 1\}, 4=\{11 \overline{2} 0\}$, and $5=\{11 \overline{2} 2\}$. (a) IM-Ti, (b) CP-Ti, and (c) Ti-1-1.

where the basal plane is parallel to either the chill or wheel surface of the specimen are typical in rapidly solidified hep metals produced via commercial chill casting or melt spinning [6,7].

Fig. 5 shows the pole figures observed in thick foils in the as cold rolled condition. Very weak ( $\sim 2 \times$ random) split deformation textures were observed where the basal poles concentrated in regions $\approx 20^{\circ}$ from the sheet normal in the rolling and transverse directions (Fig. 6). Similar transition textures have been reported by Nourbakhsh and O'Brien [8] for titanium foils cold rolled $30 \%$ at room temperature. Due to a lack of 

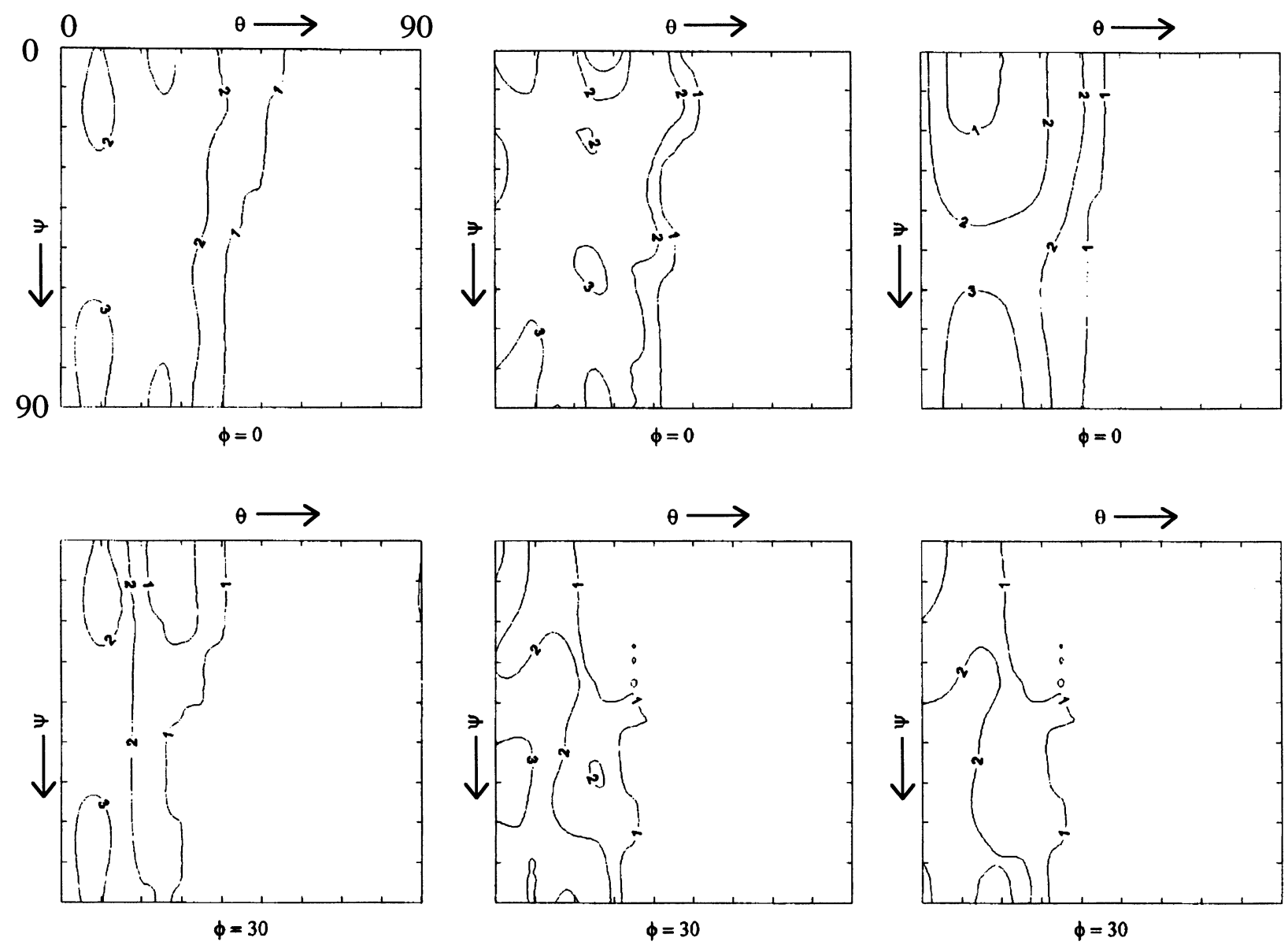

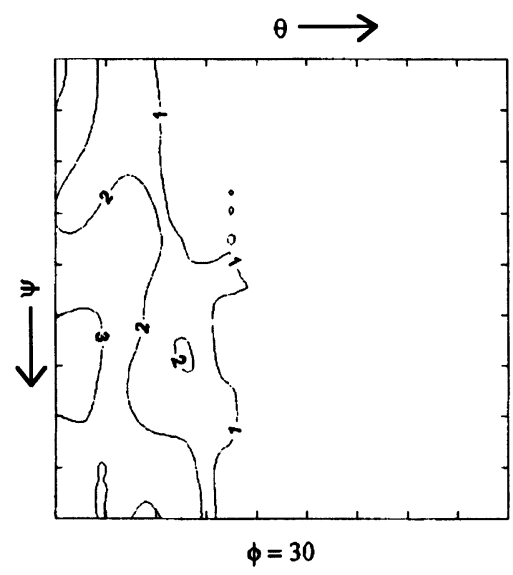

(b)

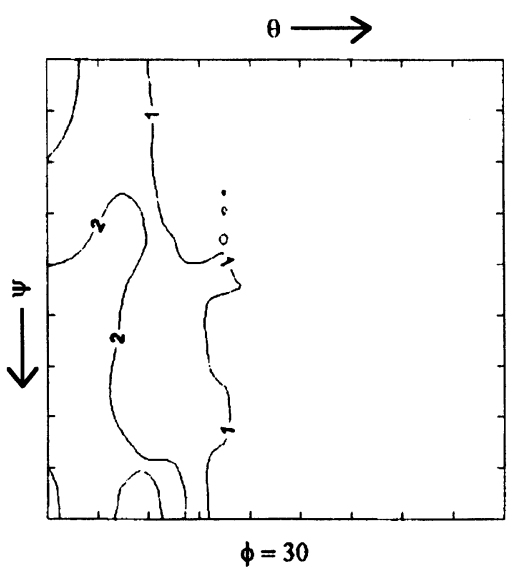

(c)

Fig. 7. $\phi=0$ and $30^{\circ} \mathrm{COD}$ sections for as-cast $\mathrm{CP}-\mathrm{Ti}$ and $\mathrm{Ti}-1-1$. (a) $\mathrm{CP}-\mathrm{Ti}$ on wheel surface, (b) $\mathrm{CP}-\mathrm{Ti}$ on free surface, and (c) Ti-1-1.

material, cold rolling textures were not measured for Ti-1-1.

Fig. 6 shows the pole figures observed after annealing at $700^{\circ} \mathrm{C}$ for $2 \mathrm{~h}$. In all of the annealed foils, split transverse direction textures were observed where the $c$-axes were concentrated in the normal direction (ND)transverse direction (TD) plane tilted $\approx 35^{\circ}$ from the ND towards the TD. Such split textures are commonly observed in IM titanium foils produced by CR [9-12]. Textures were moderate in IM-Ti $(\sim 5 \times$ random $)$ but were significantly weaker in the $\mathrm{CP}-\mathrm{Ti}$ and $\mathrm{Ti}-1-1$ foils ( $\sim 2-3 \times$ random).

Since accurate determination of the main texture components from pole figures can be difficult, particularly if more than two main orientations are simultaneously present, crystallite orientation distribution (COD) function analysis was performed using the method developed by Bunge [13] and Roe [14]. The results were then compared to recent results for commercial $\mathrm{Ti}$ [15-17].

Fig. 7 shows the $\phi=0$ and $30^{\circ}$ COD sections for DC $\mathrm{CP}-\mathrm{Ti}$ and $\mathrm{Ti}-1-1$. Texture evaluations were conducted through the thickness of the $\mathrm{CP}$-Ti strip and on the center section of the $\mathrm{Ti}-1-1$ strip. In the $\mathrm{CP}-\mathrm{Ti}$ strip, main components in the form of an orientation tube connecting the $(\overline{1} 0110)[1 \overline{2} 10]$ and (1018)[0 $\overline{1} 10]$ orientations were observed near the wheel side and in the interior of the strip. Similar main components were observed in Ti-1-1. On the free side of the $\mathrm{CP}-\mathrm{Ti}$ strip, however, only (0001)[1 $1 \overline{2} 10]$ and (1014)[4 $4 \overline{4} 01]$ main components were observed.

Fig. 8 shows the $\phi=0$ and $30^{\circ}$ COD sections for thick $\mathrm{CP}-\mathrm{Ti}$ foils in the as cold rolled condition. Through the

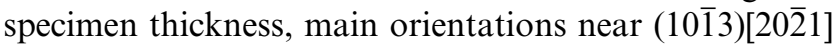
were observed. In nearly all cases the weak orientation tube obtained during casting was retained after rolling. It was additionally observed that the texture intensity was considerably greater nearer the foil edges $(7 \times$ random $)$ compared to the foil interior $(4 \times$ random $)$.

Fig. 9 shows the $\phi=0$ and $30^{\circ} \mathrm{COD}$ sections for annealed $\mathrm{CP}-\mathrm{Ti}$, Ti-1-1 and IM-Ti foils. In the CP-Ti and $\mathrm{Ti}-1-1$, main texture orientations near $(10 \overline{1} 3)[10 \overline{1} 1]$ were observed. In both foils, these orientations were relatively weak ( $\sim 3-4 \times$ random $)$. Once again, the original casting textures were retained. In the commercial IM-Ti foils, very strong $(12 \times$ random $)$ main orientations near $(\overline{1} 015)[20 \overline{2} 1]$ were observed. 

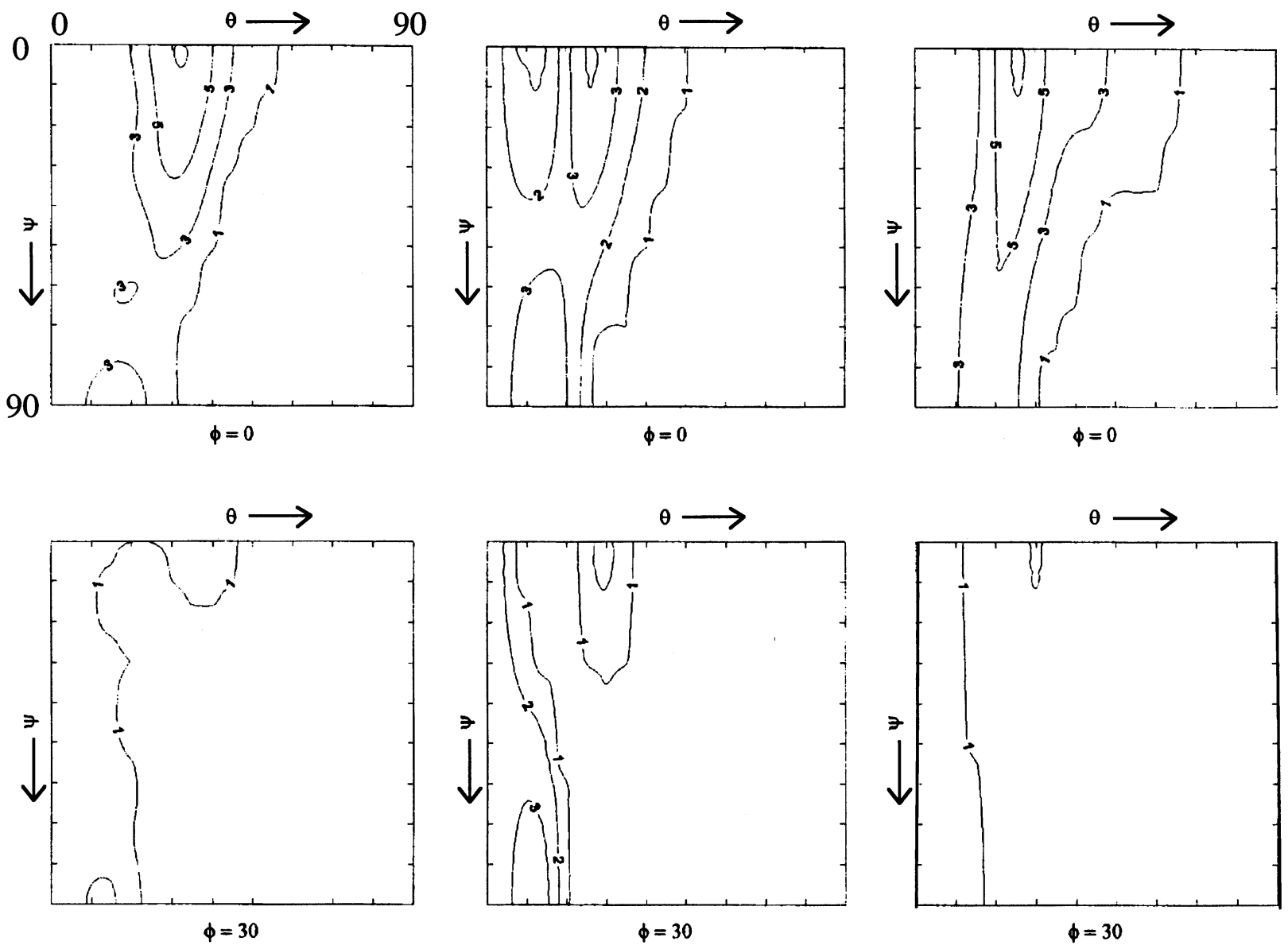

(a)

(b)

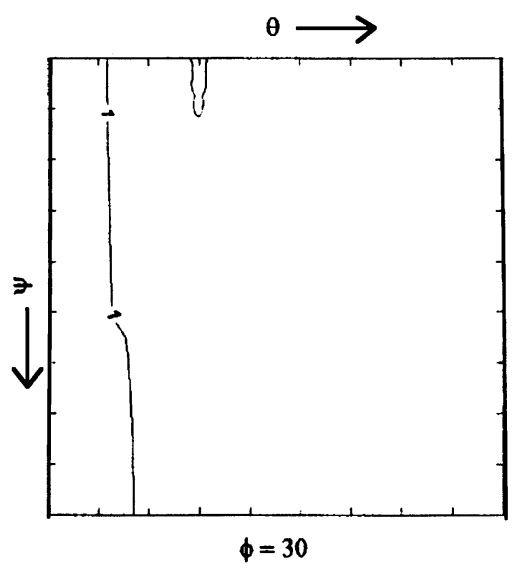

(c)

Fig. 8. $\phi=0$ and $30^{\circ} \mathrm{COD}$ sections for $\mathrm{CP}-\mathrm{Ti}$ cold rolled $40 \%$ at room temperature, (a) former wheel surface; (b) center of foil; and (c) former free surface.

\subsection{Mechanical properties}

Typical true stress versus true strain curves for the IM and DC foils are presented in Fig. 10 and the mechanical properties results are summarized in Table 2 along with the prior results of Gaspar et al. [2]. In general, the foils deformed uniformly until failure with fracture occurring in the center of the gage at an angle of $45^{\circ}$ from the tensile axis. It is difficult to make an accurate comparison of mechanical properties due to compositional and processing differences between the DC and IM foils (e.g. impurity contents, CR + A cycles, etc.), however, some general observations can be noted. In agreement with Gaspar et al. [2], the room temperature yield stress (YS) and ultimate tensile stress (UTS) exhibited a relatively small degree of anisotropy in the IM-Ti and DC CP-Ti foils. It was additionally observed that the DC $\mathrm{CP}-\mathrm{Ti}$ specimens tested in this study exhibited tensile elongations to failure that were comparable to those obtained by Gaspar et al. [2] in IM titanium. In the Ti-1-1 foils, more significant anisotropy was observed in all testing conditions. For example, in Ti-1-1 tested at a strain-rate of $7 \times 10^{-3}$ $\mathrm{s}^{-1}$, the plastic strain to failure was over two times greater in the rolling direction versus the transverse direction. It is suggested that the presence of significant anisotropy in Ti-1-1 is the result of failure to optimize the recrystallization treatment for this alloy composition and it is further believed that better mechanical properties will be realized once the $\mathrm{CR}+\mathrm{A}$ steps are further optimized.

Typical stress-strain curves for thick $\mathrm{CP}-\mathrm{Ti}$ foils tested at angles of 0,45 and $90^{\circ}$ to the rolling direction are presented in Fig. 11. The yield stress was minimum in the rolling direction and increased slightly with increasing angle from the rolling direction. Significantly greater tensile elongations were also observed parallel to the rolling direction.

\section{Discussion}

The microstructures and mechanical properties observed in the DC strips, the $\mathrm{CR}$ foil and the $\mathrm{CR}+\mathrm{A}$ 

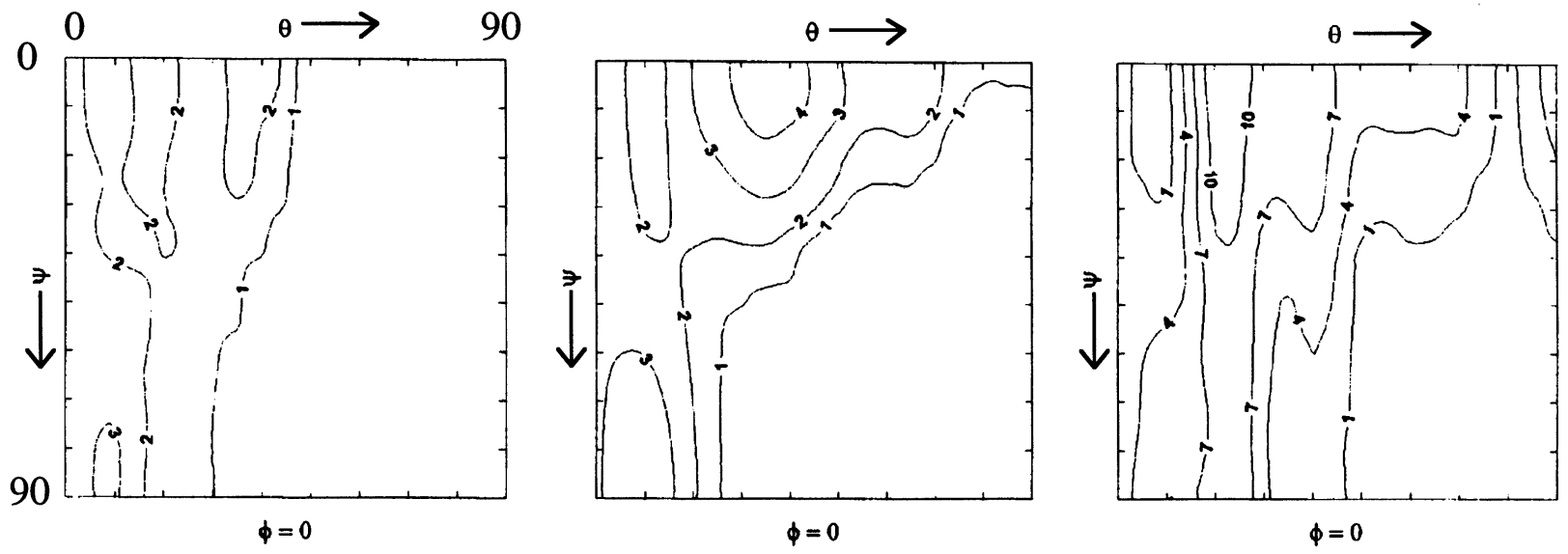

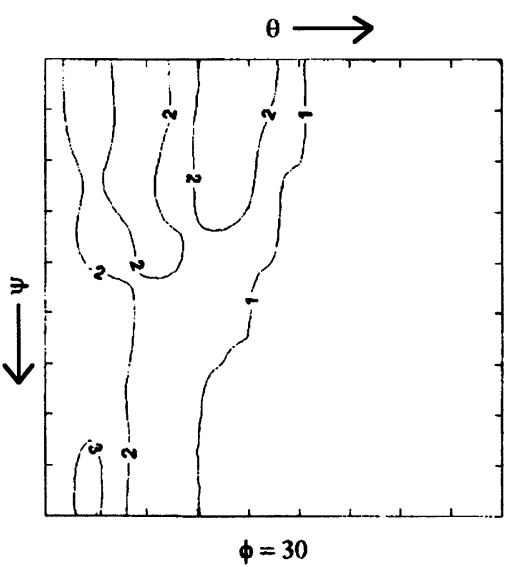

(a)

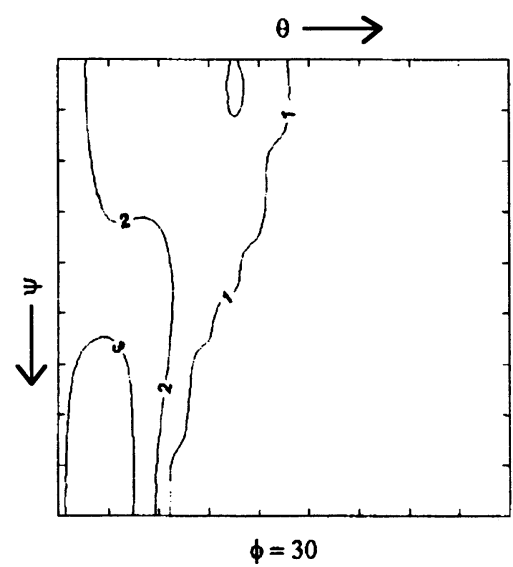

(b)

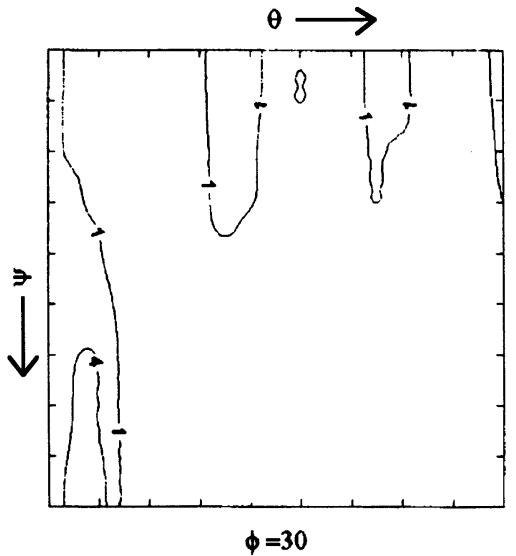

(c)

Fig. 9. $\phi=0$ and $30^{\circ} \mathrm{COD}$ sections for annealed CP-Ti, Ti-1-1, and IM-Ti foils. (a) CP-Ti, (b) Ti-1-1, and (c) IM-Ti.

foils were identical to those observed previously in DC strips [2,4] and in IM foils [2,4,18,19]. As mentioned previously, the microstructures consisted of a mixture of columnar and equiaxed grain structures in the direct cast condition, elongated grain structures after rolling, and equiaxed and recrystallized grain structures after annealing at $700^{\circ} \mathrm{C}$ for $2 \mathrm{~h}$. In addition, it has been shown that the yield stress is at a minimum in the rolling direction and that it increases with increasing angle from the rolling direction which is in qualitative agreement with prior investigations of texture and anisotropy in cold rolled titanium $[18,20,21]$.

Though cold rolling textures in titanium have been studied quantitatively using the crystallite orientation distribution function analysis (e.g. see refs. [1517,22]), discrepancies exist as to the identification of the stable end orientation. Recrystallization textures are extremely sensitive to the amount of rolling reduction and the annealing temperature. As summarized by Inagaki [18], recrystallization textures formed at temperatures below $500^{\circ} \mathrm{C}$ are similar to rolling textures consisting of the (0001)[1010] main orientation tilted $40^{\circ}$ towards the transverse direction (component A). At temperatures between 500 and $700^{\circ} \mathrm{C}$, where minimal grain growth occurs, dual textures consisting of and main orientations tilted $30^{\circ}$ towards the transverse direction TD (component B) exist. At temperatures above $700^{\circ} \mathrm{C}$, where significant grain growth occurs, only (0001)[12 10$]$ orientations develop (component C). Components A, B and $\mathrm{C}$ have been identified with the crystallite orientation distribution analysis as: $(\overline{2} 115)[0 \overline{1} 10]$; an orientation tube connecting the $(\overline{2} 115)[0 \overline{1} 10]$ and $(\overline{1} 013)[1 \overline{2} 10]$ orientations; and either $(10 \overline{1} 3)[1 \overline{2} 10]$ or $(\overline{2} 025)[1 \overline{2} 10]$, respectively. The casting texture can be justified by the solidification process itself which should result in a slightly rotated fiber texture with the basal poles oriented parallel to the direction of heat flow near the wheel side of the specimen and in a more random texture near the free surface. This reflects the breakdown of the microstructure from columnar to equiaxed as the 
free surface of the specimen is approached. The wheel side orientation, which is in the form of an orientation tube near $(\overline{1} 0110)[1 \overline{2} 10]$ and $(1 \overline{2} 18)[0 \overline{1} 10]$, is approximately a $10^{\circ}$ rotation about the [0001] axis parallel to the casting direction. Considering the nature of the solidification microstructures as described above, such an orientation is at least justified. On the free side of the specimen the presence of $(0001)[1210]$

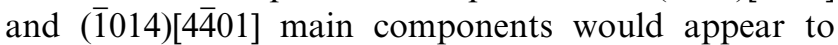
support this interpretation. The rolling and annealing textures, however, do not correspond directly with published literature. The results generated in this study indicate main texture orientations of

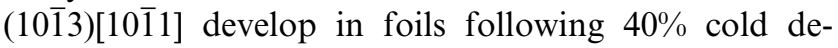
formation and annealing at $700^{\circ} \mathrm{C}$ for $2 \mathrm{~h}$ which are rotated $\approx 10^{\circ}$ from the basal plane towards [1010]. Further investigations are in progress to determine the nature of these unique textures, however, it is tentatively suggested that these textures are a result of the lattice rotations and nonuniform cooling that occur during the casting process.
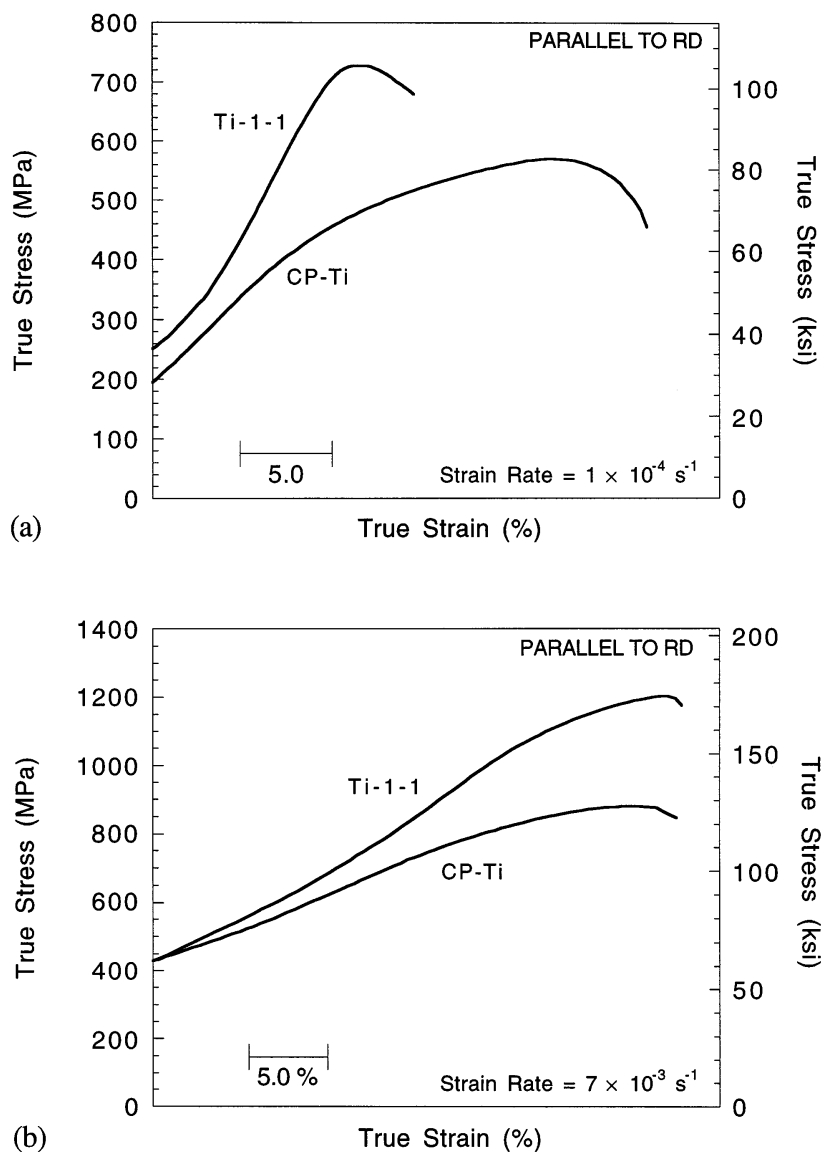

Fig. 10. Typical true stress versus true strain curves for IM and DC foils tested parallel to the rolling direction at two different strain rates. (a) Strain rate $=1 \times 10^{-4} \mathrm{~s}^{-1}$ and (b) strain rate $=7 \times 10^{-3}$ $\mathrm{s}^{-1}$.

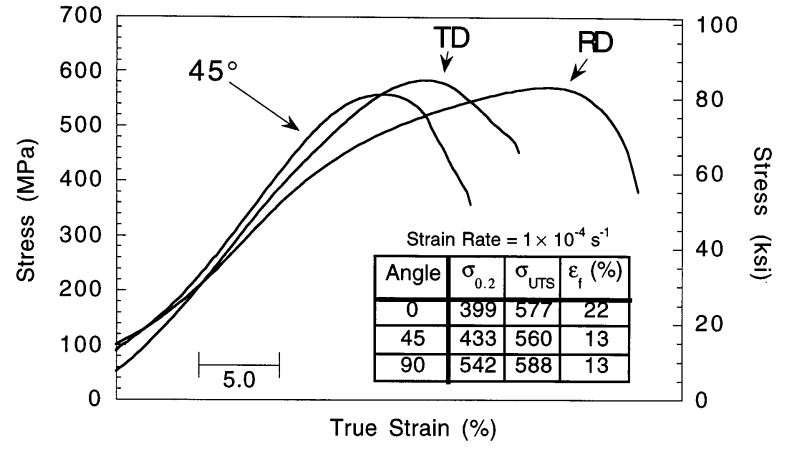

Fig. 11. Typical true stress vs true strain curves at angles of 0,45 and $90^{\circ}$ with respect to the rolling direction for $\mathrm{CP}-\mathrm{Ti}$ cold rolled $40 \%$ at room temperature (strain rate $=1 \times 10^{-4} \mathrm{~s}^{-1}$ ).

\section{Summary and conclusions}

In general, this study has confirmed prior reports that high quality DC foils with mechanical properties comparable to IM foils can be successfully produced using the MORST process. Furthermore, these foils exhibit the same microstructures and textures as IM processed foils. Interstitial contents are lower in DC $\mathrm{CP}-\mathrm{Ti}$ compared to IM-Ti foils. The DC foils were fully dense and exhibited equiaxed transformed grain structures and weak $\{11 \overline{2} 0\} / /$ normal direction solidification textures. After cold rolling, split $\{0002\}$ textures were observed in both DC and ingot metallurgy (IM) processed foils with the basal poles concentrated $\approx 30^{\circ}$ from the normal direction towards the transverse direction. Crystallite orientation distribution function analysis indicated the presence of an orientation tube at the wheel surfaces in the cast specimens

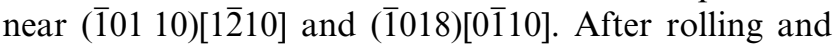
annealing, main texture orientations of $(10 \overline{1} 3)$ [10 11$]$ were observed. It is suggested that these textures are a result of the lattice rotations and nonuniform cooling that occur during the casting process. Mechanical properties evaluations revealed that the mechanical properties of the DC foils were comparable to IM foils. The results suggest that high quality titanium foils can be processed via MORST without the need for costly and wasteful hot rolling and annealing steps resulting in reduced processing costs. Further improvements in mechanical properties can be realized through optimization of the rolling and annealing processes.

\section{Acknowledgements}

This research was supported by the NASA-Center for Nonlinear and Nonequilibrium AeroScience at 
Table 2

Tensile properties of CP-Ti foils

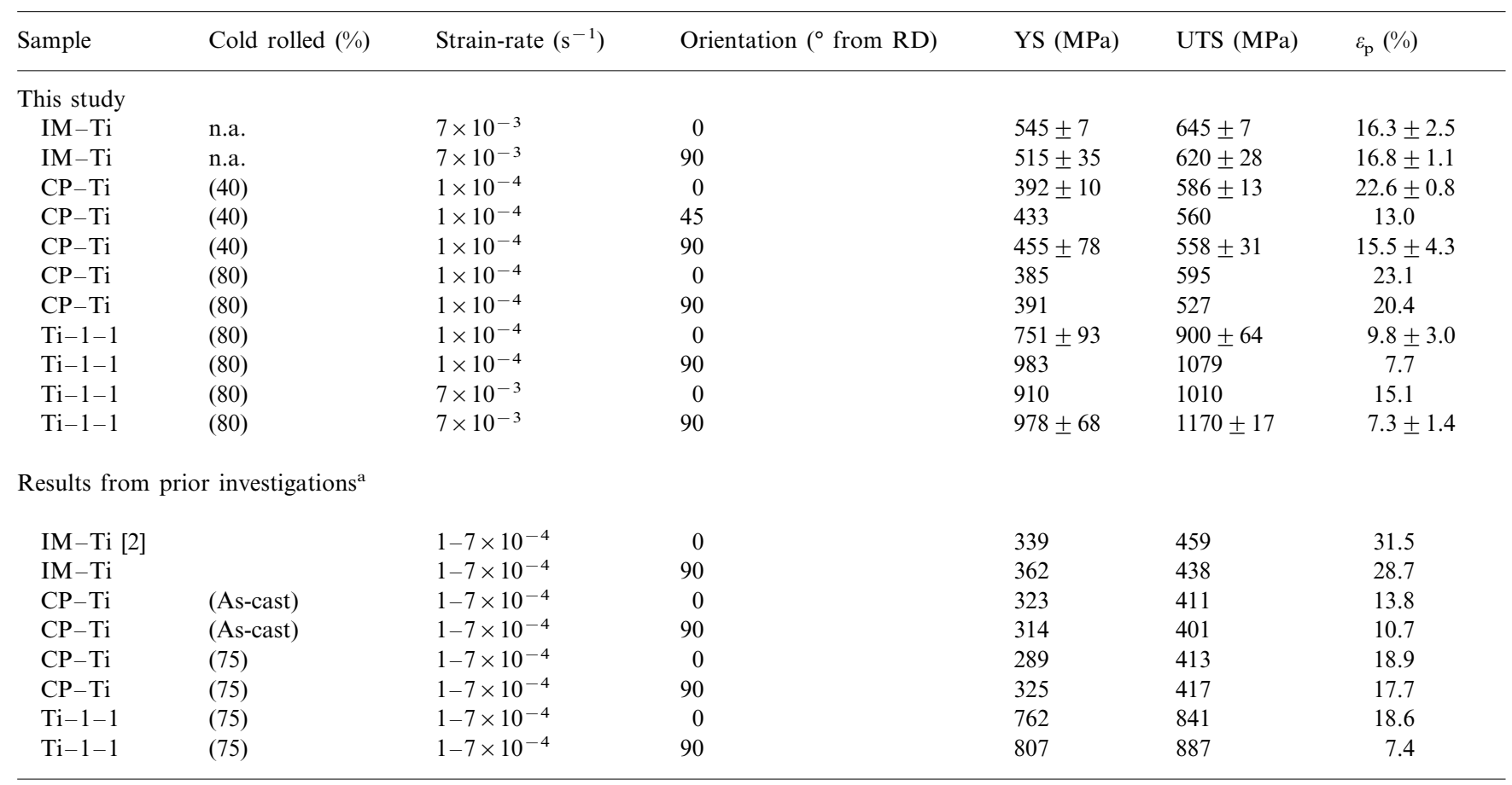

${ }^{a}$ Specimens tested in ref. [2] were deformed at an intitial strain rate of $1 \times 10^{-4} \mathrm{~s}^{-1}$ until yield and then deformed at $7 \times 10^{-4} \mathrm{~s}^{-1}$ until fracture.

Florida A and M University and by the NASA-Langley Research Center under the Faculty Awards for Research Program (grant no. NAG-1-1866).

\section{References}

[1] T.A. Gaspar, L.E. Hackman, Mater. Sci. Eng. A133 (1991) $676-679$.

[2] T.A. Gaspar, T.A. Stuart, I.M. Sukonnik, S.L. Semiatin, E. Batawi, J.A. Peters, H.L. Fraser, Producing Foils From Direct Cast Titanium Alloy Strip, Ribbon Technology, Contractor Report no. NASA CR-4742, May 1996.

[3] T.A. Gaspar, L.E. Hackman, E. Batawi, J.A. Peters, Mater. Sci. Eng. A170/A180 (1994) 645-648.

[4] T.A. Gaspar, I.M. Sukonnik, R.K. Bird, W.D. Brewer, in: F.H. Froes, C. Suryanarayana, C.M. Ward-Close (Eds.), Synthesis/ Processing of Lightweight Metallic Materials, The Minerals, Metals and Materials Society, Las Vegas, NV, 1995, pp. 119128.

[5] J. Kallend, U.F. Kocks, A.D. Rollett, H.-R. Wenk, Mater. Sci. Eng. A132 (1991) 1-11.

[6] M.V. Akdeniz, J.V. Wood, Mater. Sci. Forum 157/162 (1994) 1351-1356.

[7] N.W. Blake, R.W. Smith, Can. J. Phys. 60 (1982) 1720-1724.

[8] S. Nourbakhsh, T. O’Brien, Mater. Sci. Eng. 100 (1988) 109114.

[9] M.J. Philippe, F. Wagner, C. Esling, in: J.S. Kallend, G. Gottstein (Eds.), 8th International Conference on Textures of
Metals, The Metallurgical Society, Santa Fe, NM, 1988, pp. $837-842$.

[10] W.F. Hosford in: A.L. Cullen, L.C. Woods, J.M. Brady, C. Brennen, W.R.E. Taylor, M.Y. Hussaini, T.V. Jones, J.V. Bladel, (Eds.), Oxford Engineering Science Series, Oxford University Press, New York, 1993.

[11] E. tenckhoff, Deformation Mechanisms, Texture and Anisotropy in Zirconium and Zircaloy, American Society for Testing and Materials, vol. STP 966, Philadelphia, PA, 1988.

[12] D.R. Thornburg, H.R. Piehler, in: R.I. Jaffee, H.M. Burte (Eds.), 2nd International Conference on Titanium Science and Technology, Vol. 2, Plenum Press, Cambridge, MA, 1973, pp. $1187-1197$.

[13] H.J. Bunge, Texture Analysis in Materials Science, Butterworth, London, 1982.

[14] J. Roe, J. Appl. Phys. 36 (1965) 2024-2031.

[15] H. Inagaki, Zietschrift fur Metallkunde 82 (1991) 779-789.

[16] H. Inoue, N. Inakazu, in: J.S. Kallend, G. Gottstein (Eds.), ICOTOM 8, The Minerals, Metals and Materials Society, Warrendale, PA, 1988, pp. 997-1004.

[17] P. Dervin, J.P. Mardon, M. Pernot, R. Penelle, P. Lacombe, J. Less Common Met. 55 (1977) 25-43.

[18] H. Inagaki, Zietschrift fur Metallkunde 83 (1992) 40-46.

[19] M. Blicharski, S. Nourbakhsh, J. Nutting, Met. Sci. J. 13 (1979) $516-522$.

[20] R.A. Fishburn, W.T. Roberts, D.V. Wilson, Met. Technol. 3 (1976) 310-321.

[21] D.H. Rogers, W.T. Roberts, Int. J. Mech. Sci. 10 (1968) 221229.

[22] P.R. Morris, A.J. Heckler, Trans. Metall. Soc. AIME 245 (1969) $1877-1881$. 